Pan American Health Organization \& World Health Organization (2007) Perfil De Los Sistemas De Salud De La Republica Dominicana: Monitoreo y Analisis De Los Procesos De Cambios y Reforma [Dominican Republic Health System Profile] (3rd edition). PAHO/WHO.

Pan American Health Organization \& World Health Organization (2008) Report on the Assessment of Mental Health Systems in the Dominican Republic Using the WHO Assessment Instrument for Mental Health Systems (WHO-AIMS). PAHO/WHO. Available at http://www.who. int/mental_health/dominican_republic_who_aims_eng.pdf (accessed October 2010).

Sánchez Martínez, F. (2006) Psiquiatría Dominicana [Dominican Psychiatry], pp. 98, 104, 262-264, 275-277. Editora Búho.

World Health Organization (2005) Mental Health Atlas: Dominican Republic, pp. 172-173. WHO. Available at http://www.who.int/ mental_health/evidence/atlas/profiles_countries_c_d.pdf (accessed October 2010).

\title{
Perceived coercion and need for hospital admission among psychiatric in-patients: figures from a Pakistani tertiary care hospital
}

\section{Saman I. Zuberi FCPS, ${ }^{1}$ Ayesha Sajid MD, ${ }^{2}$ Abdul Wahab Yousafzai FCPS, ${ }^{3}$ Naila Bhutto FCPS ${ }^{4}$ and Murad Moosa Khan MRCPsych ${ }^{5}$}

\begin{abstract}
'Department of Psychiatry, Aga Khan University, Karachi, Pakistan, email saman.yousuf.zuberi@gmail.com; ${ }^{2}$ PGYII, Department of Psychiatry, Indiana University School of Medicine, USA; ${ }^{3}$ Assistant Professor, Department of Psychiatry, Ayub Medical College and Visiting Faculty, Department of Psychiatry, Aga Khan University; ${ }^{4}$ nstructor and Consultant Psychiatrist, Department of Psychiatry, Aga Khan University; ${ }^{5}$ Chair, Department of Psychiatry, Aga Khan University Hospital
\end{abstract}

\begin{abstract}
n Pakistan, an increasing proportion of psychiatric patients present to community health services as crisis admissions, with their relatives as the main decision makers. Patients are bound to perceive this process as coercive. Farnham \& James (2000) report that elements of coercion are found even in voluntary hospital admission, in the form of verbal persuasion, physical force and threats of commitment. Few patients consider hospitalisation justified and most view the process of admission negatively (Swartz et al, 2003; Katsakou \& Priebe, 2006; Priebe et al, 2009).

Perceptions of coercion depend on context and are subject to cultural differences. Unfortunately, there is no study from Pakistan, a low-income country with unregulated mental health services, where sections of Mental Health Act 2001 are loosely followed at best (Gilani et al, 2005). Most mental health facilities define 'involuntary admission' as the situation where the family brings a patient against his or her will and a physician takes a decision after assessment without due legal procedures or recourse to appeal.

We explored perceptions of coercion and hospitalisation among patients admitted to a psychiatric unit in Karachi. The unit accepts compulsory admissions advised by courts for assessment (this is uncommon). The Mental Health Act 2001 is not used formally. We looked for associated patient characteristics.
\end{abstract}

\section{Method}

Patients admitted to the psychiatric in-patient unit (a 16-bed adult unit) of Aga Khan University Hospital were sampled. Patients 18 years or older, admitted with any psychiatric diagnosis, were enrolled. Younger patients and those with intellectual disability, cognitive impairment or acute psychotic symptoms were excluded. Patient characteristics were recorded: gender, age, marital status, language, occupation and education, clinical diagnosis, admission type (first $v$. repeat) and nature (voluntary $v$. involuntary).

Each patient was administered the MacArthur Admission Experience Survey (AES; Nicholson et al, 1996), which comprises 15 items in a true/false format. This scale was translated into Urdu by bilingual translators and administered to 20 patients before the study. Difficulties were resolved by consensus. The AES has good internal reliability (Gardner et al, 1993). It contains four subscales with yes/no responses: the Perceived Coercion Scale (PCS, 5 items), which has an equivalent consistency and test-retest reliability, the Negative Pressures Scale (NPS, 6 items), the Voice/Process Exclusion Scale (PES, 3 items) and the Affective Reactions to Hospitalisation Scale (1 item). Scoring involved summing over the whole scale (except items 9 and 15) as well as the first three subscales, as has been done in other studies (Gardner et al, 1993). A cut-off score of 2 on the PCS was used to split 
Table 1 Sample characteristics $(n=87)$

\begin{tabular}{|c|c|}
\hline Variables & Frequency (\%) \\
\hline $\begin{array}{l}\text { Gender } \\
\text { Male } \\
\text { Female }\end{array}$ & $\begin{array}{l}46(53) \\
41(47)\end{array}$ \\
\hline $\begin{array}{l}\text { Age (years) } \\
\text { Less than } 30 \\
31-50 \\
\text { More than } 50\end{array}$ & $\begin{array}{l}37(43) \\
34(39) \\
16(18)\end{array}$ \\
\hline $\begin{array}{l}\text { Marital status } \\
\text { Single } \\
\text { Married }\end{array}$ & $\begin{array}{l}41(47) \\
46(53)\end{array}$ \\
\hline $\begin{array}{l}\text { Education } \\
\text { Illiterate } \\
\text { Undergraduate } \\
\text { Graduate and above }\end{array}$ & $\begin{array}{r}9(10) \\
42(48) \\
36(41)\end{array}$ \\
\hline $\begin{array}{l}\text { Occupation } \\
\text { Student } \\
\text { Professional } \\
\text { Retired } \\
\text { Unemployed/housewife } \\
\text { Business } \\
\text { Unskilled or skilled worker }\end{array}$ & $\begin{aligned} 14 & (16) \\
12 & (14) \\
7 & (8) \\
11 & (13) \\
27 & (31) \\
16 & (18)\end{aligned}$ \\
\hline $\begin{array}{l}\text { Ethnicity } \\
\text { Urdu-speaking } \\
\text { Pathan } \\
\text { Sindhi } \\
\text { Punjabi } \\
\text { Balochi } \\
\text { Other }\end{array}$ & $\begin{array}{c}41(47) \\
16(18) \\
15(17) \\
9(10) \\
2(2) \\
4(5)\end{array}$ \\
\hline $\begin{array}{l}\text { Diagnosis } \\
\text { Substance misuse } \\
\text { Mood disorders } \\
\text { Anxiety and stress-related disorders } \\
\text { Schizophrenia and other psychotic disorders }\end{array}$ & $\begin{array}{r}14(16) \\
38(44) \\
9(10) \\
26(30)\end{array}$ \\
\hline $\begin{array}{l}\text { Type of admission } \\
\text { First } \\
\text { Repeat }\end{array}$ & $\begin{array}{l}57(66) \\
30(34)\end{array}$ \\
\hline $\begin{array}{l}\text { Nature of admission } \\
\text { Voluntary } \\
\text { Involuntary }\end{array}$ & $\begin{array}{l}53(61) \\
34(39)\end{array}$ \\
\hline
\end{tabular}

the sample into 'high coercion' and 'low coercion' groups, as in a previous study (Iversen et al, 2007). For the NPS and PES, scores above the mean value were considered 'high' and those below 'low'.

Written informed consent was taken. The study was approved by the hospital's ethics committee. An interviewer experienced in psychiatric interviewing was hired to administer the questionnaire within first 24 hours of admission.

Data were analysed using the Statistical Package of Social Sciences (version 16.0). Frequency distributions were determined and data dispersion for each subscale of the AES examined. Chi-square tests of association and regression analysis looked for differences between those scoring high and low on the PCS.

\section{Results}

In total, 101 patients were approached; 14 patients declined to participate, giving an $86 \%$ response rate. Table 1 details the sample characteristics.

On the PCS, the mean (s.d.) score was 3.06 (2.09). Overall, $70 \%$ of the sample had a 'high' PCS score (2 or
Table 2 Comparison of characteristics of patients with low and high coercion scores

\begin{tabular}{|c|c|c|c|}
\hline \multirow[t]{2}{*}{ Variables } & \multicolumn{2}{|c|}{ Frequency (\%) } & \multirow[t]{2}{*}{$P$-value } \\
\hline & Low score & High score & \\
\hline $\begin{array}{l}\text { Gender } \\
\text { Male } \\
\text { Female }\end{array}$ & $\begin{array}{l}18(39.1) \\
15(36.6)\end{array}$ & $\begin{array}{l}28(60.9) \\
26(63.4)\end{array}$ & 0.807 \\
\hline $\begin{array}{l}\text { Age (years) } \\
\text { Less than } 30 \\
31-50 \\
\text { More than } 50\end{array}$ & $\begin{array}{r}20(54.1) \\
11(32.4) \\
2(12.5)\end{array}$ & $\begin{array}{l}17(45.9) \\
23(67.6) \\
14(87.5)\end{array}$ & $0.012^{*}$ \\
\hline $\begin{array}{l}\text { Marital status } \\
\text { Single } \\
\text { Married }\end{array}$ & $\begin{array}{l}22(53.7) \\
11(23.9)\end{array}$ & $\begin{array}{l}19(46.3) \\
35(76.1)\end{array}$ & $0.004^{*}$ \\
\hline $\begin{array}{l}\text { Education } \\
\text { Illiterate } \\
\text { Undergraduate } \\
\text { Graduate and above }\end{array}$ & $\begin{array}{r}3(33.3) \\
16(38.1) \\
14(38.9)\end{array}$ & $\begin{array}{r}6(66.7) \\
26(61.9) \\
22(61.1)\end{array}$ & 0.953 \\
\hline $\begin{array}{l}\text { Diagnosis } \\
\text { Substance misuse } \\
\text { Mood disorders } \\
\text { Anxiety and stress-related } \\
\quad \text { disorders }\end{array}$ & $\begin{aligned} 1 & (7.1) \\
12 & (31.6) \\
5 & (55.6)\end{aligned}$ & $\begin{array}{r}13(92.9) \\
26(68.4) \\
4(44.4)\end{array}$ & \\
\hline $\begin{array}{l}\text { Schizophrenia and other } \\
\text { psychotic disorders }\end{array}$ & $15(57.7)$ & $11(42.3)$ & $0.008 *$ \\
\hline $\begin{array}{l}\text { Type of admission } \\
\text { First } \\
\text { Repeat }\end{array}$ & $\begin{array}{l}20(35.1) \\
13(43.3)\end{array}$ & $\begin{array}{l}37(64.9) \\
17(56.7)\end{array}$ & 0.451 \\
\hline $\begin{array}{l}\text { Nature of admission } \\
\text { Voluntary } \\
\text { Involuntary }\end{array}$ & $\begin{array}{r}6(11.3) \\
27(79.4)\end{array}$ & $\begin{array}{r}47(88.7) \\
7(20.6)\end{array}$ & $<0.001 *$ \\
\hline
\end{tabular}

more); strikingly, only $21 \%$ involuntary patients scored 'high' on this subscale, compared with $89 \%$ of voluntary admissions. All patients with a diagnosis of substance misuse or mood disorder who were voluntarily admitted perceived high coercion.

Table 2 shows the differences between the high and low PCS groups. Participants older than 30 years were twice as likely to report high PCS scores. Similarly, having a diagnosis of substance misuse or mood disorder increased the likelihood seven-fold $(P=0.014)$ and four-fold $(P=0.04)$, respectively, while a diagnosis of psychotic disorder reduced the likelihood by six times $(P=0.013)$. Voluntary admission predicted a high PCS score even after controlling for demographic and clinical characteristics $(P<0.001)$.

The mean (s.d.) score on the NPS was 2.07 (1.03); $41 \%$ of involuntary and $21 \%$ of voluntary admissions scored 'high'. The mean (s.d.) score on the PES was 1.75 (0.53); 44\% of involuntary and $41 \%$ of voluntary patients scored 'high'. Both differences were statistically significant.

The affective reactions to hospitalisation reported were as follows: one-third were angry and frightened, whereas $63 \%$ were sad; another $46 \%$ were confused; only $30 \%$ were pleased with the process of hospitalisation; a further $52 \%$ felt relieved. These reactions were not significantly different between voluntary and involuntary admissions but, overall, those with high PCS scores were more likely to be angry and relieved than those with a low score. 


\section{Discussion}

Our sample was from a private tertiary care hospital in Karachi, one of the major cities of Pakistan. The demographic characteristics of the participants were similar to the patient profile of all attenders at the hospital. The majority were experiencing hospitalisation for the first time. Nearly half had a diagnosis of mood disorder; psychotic disorders were the next most common category.

A high proportion reported feeling coerced in the hospitalisation process. A qualitative study from Switzerland (Bonsack \& Borgeat, 2005) and another that used the AES on a Norwegian sample (Iversen et al, 2007) have reported similar findings. Surprisingly, a greater proportion of voluntary admissions compared with involuntary ones perceived coercion. This was a counter-intuitive finding which could be the result of a small sample size or either sample being atypical, as it was not specific to any diagnosis. It needs to be replicated. Negative pressures were, though, felt more in involuntary admissions and in nearly half of voluntary and involuntary admission patients felt they were excluded from the hospitalisation process. These findings support previous observations (Fu et al, 2008), although the present figure is much higher. Most of the voluntary admissions were patients with mood disorder; stigma related to hospitalisation as well as illness perception could have contributed to feelings of coercion. A diagnosis of substance misuse was also associated with higher coercion. Disapproval of any form of substance misuse in the local culture often results in families bringing patients in a pre-contemplative stage. External pressures, especially marital (from spouse or in-laws) and parental, are common. Moreover, many of these patients could have an underlying personality disorder, which might have contributed to this perception.

Having a psychotic illness was not associated with high coercion scores, though this has been reported by others (Hiday et al, 1997; Fu et al, 2008), but there was a small number of such patients in the present sample.

Being married was associated with higher coercion, similar to previous studies (Bonsack \& Borgeat, 2005; Katsakou \& Priebe, 2006). Marital pressures in the local culture may have caused this. Participants older than 30 years felt a higher degree of coercion; this may reflect diagnosis, however, since patients with substance misuse or mood disorder usually present at that age. There was no association of gender, education or type of admission (first $v$. repeat) with feelings of coercion. Hiday et al (1997) found an association with female gender and education in 331 individuals; our negative finding could have resulted from our much smaller sample size.

Those with higher coercion scores were also more likely to be both angry and relieved. This suggests that the perception of coercion is independent of the need for hospitalisation. Our study confirms an observation by Bonsack \& Borgeat (2005) that this distinction does not depend on duration of hospital stay; our patients showed it within 24 hours of admission.
Limitations of the study include the fact that the sample was not representative of patients across Pakistan, and so, for example, no general comment can be made on the need for mental health legislation. Also, a comparison of participants with those who declined could not be made; this may have introduced selection bias. The MacArthur questionnaire was not validated against the English version or other objective measures of coercion. The yes/no response style of the question is restrictive. Lastly, the source of coercion was not explored.

\section{Conclusions and recommendations}

A significant proportion of patients admitted on even a voluntary basis perceived a high degree of coercion in the process of hospitalisation. Patients with a diagnosis of substance misuse or mood disorder perceived significantly more coercion. There is need for larger surveys as well as improved planning and communication between patient, family and hospital staff during hospitalisation. Mental health legislation needs to be revisited with these conclusions in mind and mental health practices across the country need to be standardised.

\section{References}

Bonsack, C. \& Borgeat, F. (2005) Perceived coercion and need for hospitalization related to psychiatric admission. International Journal of Law and Psychiatry, 28, 342-347.

Farnham, F. R. \& James, D. V. (2000) Patients' attitudes to psychiatric hospital admission. Lancet, 355, 594.

Fu, J. C. K., Chow, P. P. L. \& Lam, L. C. W. (2008) The experience of admission to psychiatric hospital among Chinese adult patients in Hong Kong. BMC Psychiatry, 8, 86.

Gardner, W., Hoge, S., Bennett, N., et al (1993) Two scales for measuring patients' performance perceptions of coercion during hospital admission. Behavioral Sciences and the Law, 20, 307-321.

Gilani, A. I., Gilani, U. I., Kasi, P. M., et al (2005) Psychiatric health laws in Pakistan: from lunacy to mental health. PLoS Medicine, 2, e317.

Hiday, V. A., Swartz, M. S., Swanson, J., et al (1997) Patient perceptions of coercion in mental hospital admission. International Journal of Law and Psychiatry, 20, 227-241.

Iversen, K. I., Høyer, G. \& Sexton, H. C. (2007) Coercion and patient satisfaction on acute psychiatric wards. International Journal of Law and Psychiatry, 30, 504-511.

Katsakou, C. \& Priebe, S. (2006) Outcomes of involuntary hospital admissions - a review. Acta Psychiatrica Scandinavica, 114, 232-241.

Nicholson, R. A., Ekenstam, C. \& Norwood, S. (1996) Coercion and outcome of psychiatric hospitalization. International Journal of Law and Psychiatry, 19, 201-217

Priebe, S., Katsakou, C., Amos, T., et al (2009) Patients' views and readmissions 1 year after hospitalisation. British Journal of Psychiatry, 194, 49-54.

Swartz, M. S., Swanson, J. W. \& Hannon, M. J. (2003) Does fear of coercion keep people away from mental health treatment? Evidence from a survey of persons with schizophrenia and mental health professionals. Behavioral Sciences and the Law, 21, 459-472. 